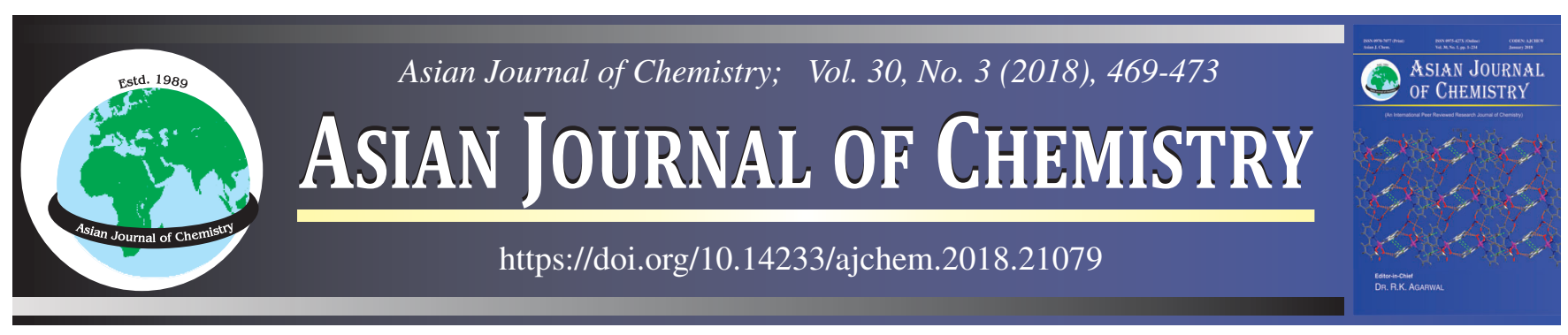

REVIEW

\title{
Zinc Telluride Thin Films: A Review
}

\section{S.M. Ho ${ }^{1, *}$, O.I. Olusola ${ }^{2}$, D.C. Sharma ${ }^{3}$ and W. MahmoOD ${ }^{4}$}

${ }^{1}$ Centre for Green Chemistry and Applied Chemistry, INTI International University, Putra Nilai 71800, Negeri Sembilan, Malaysia ${ }^{2}$ Condensed Matter and Statistical Physics Research Unit, Department of Physics, School of Science, The Federal University of Technology, Akure, P.M.B. 704, Nigeria

${ }^{3}$ Department of Physics, Kautilya Institute of Technology \& Engineering, ISI-16, RIICO Institutional Area, Sitapura, Jaipur-302 022, India ${ }^{4}$ Department of Physics, Fatima Jinnah Women University, The Mall, Rawalpindi, Pakistan

*Corresponding author: Tel: +60 6 7982000, E-mail: soonmin.ho@newinti.edu.my

Received: 6 October 2017;

Accepted: 29 November 2017;

Published online: 31 January 2018;

AJC-18725

Zinc telluride thin films can be used in a large variety of applications such as optoelectronics and microelectronics tools. In this paper, the growth of ZnTe films prepared by electrodeposition, thermal evaporation and closed space sublimation method with various precursors and some its physical properties of obtained zinc telluride films are discussed.

Keywords: Zinc telluride, Thin films, Electrodeposition, Thermal evaporation.

ᄂ - - - - - - - - - - - - - - - -

\section{INTRODUCTION}

Extensive research has been carried out on the deposition and characterization of polycrystalline thin films by several researchers [1-32]. These materials are used in optical instruments, solar cells, telecommunications terminals, in-vehicle equipment, traffic lights, magnetic films, diamond films, microelectronic devices, solar selective coatings, sensor devices, optical mass memories and superconducting films. In recent years, binary semiconductor material such as zinc telluride has been studied by many scientists. Recent investigations have shown that zinc telluride thin films show absorption in the spectrum range from visible to near infrared (as widely reported in the literature). The II-VI (ZnTe) compound semiconductors have a direct transition at $2.26 \mathrm{eV}$. Therefore, $\mathrm{ZnTe}$ is capable of green light emission at $550 \mathrm{~nm}$, i.e. in spectral region corresponding to the maximum sensitivity of the human eye. This makes ZnTe an appealing candidate for the production of bright light-emitting diodes and diode lasers. There are several reports available on the growth of zinc telluride thin films by different deposition methods such as electro-deposition method [33-35], closed space sublimation technique [36,37], screen printing technique [38], spray pyrolysis [39], radio frequency magnetron sputtering [40], thermal evaporation [41], electron beam evaporation [42], physical vapour deposition [43] and molecular beam epitaxy [44]. Each technique has strengths and weaknesses as described by researchers.
In this paper, we report the preparation of zinc telluride thin films using electrodeposition, thermal evaporation and closed space sublimation technique. Investigations of physical properties of obtained zinc telluride films are also described.

Electrodeposition method: Among the several techniques used in the development of ZnTe thin films, electrodeposition technique offers a lot of advantages among which are simplicity of achieving $n$ - and $p$-type electrical conductivity [45], ease of band gap tenability [46], good control of thickness of thin films by adjusting the growth voltage and time. Various researchers have carried out numerous works on the fabrication of ZnTe semiconductors and associated devices using electrodeposition techniques from aqueous and non-aqueous solutions. The optical, electrical, structural, morphological and compositional properties of ZnTe semiconductors have been well investigated and reported. The preparation of $\mathrm{ZnTe}$ thin films using a simple two-stage electrodeposition process was first described by Basol and Kapur [47]. By applying electrodeposition technique, Neumann-Spallart and Königstein [48] used aqueous acidic solutions comprising of $\mathrm{K}_{2} \mathrm{SO}_{4}$ as supporting electrolyte, $\mathrm{ZnSO}_{4}$ as $\mathrm{Zn}$ precursor and $\mathrm{TeO}_{2}$ as Te precursor in obtaining $p$-type ZnTe films.

Mahalingam et al. [49] carried out the investigations by using $\mathrm{ZnSO}_{4}$ and $\mathrm{TeO}_{2}$ precursors with $\mathrm{Na}_{2} \mathrm{SO}_{4}$ supporting electrolyte and observed that the electrical conductivity type of electrodeposited ZnTe films remains $p$-type despite the variations in the growth temperature. Fauzi et al. [50] employed 
$\mathrm{TeO}_{2}$ as Te precursor and $\mathrm{ZnCl}_{2}$ as $\mathrm{Zn}$ precursor different from the ones used by Neumann-Spallart and Königstein [48] to electroplate $p$-type ZnTe films from an aqueous acidic bath. Diso et al. [51] studied the effect of using two different $\mathrm{Zn}$ precursors which are $\mathrm{ZnSO}_{4}$ and $\mathrm{ZnCl}_{2}$ on the optoelectronic properties of electroplated ZnTe semiconductors. They observed that the electrical conductivity type of ZnTe materials made from the two different baths remain the same as $p$-type while the optical properties vary. Other researchers [52,53] used aqueous solutions in an acidic medium to electroplate ZnTe films with $p$-type electrical conductivity. The electrodeposition of $\mathrm{ZnTe}$ thin films using a non-aqueous solution have also been successfully demonstrated by Chaure et al. [54], Islam et al. [55] and Gandhi et al. [56].

Considering most of the ZnTe films grown by conventional methods, it was observed that they were mainly $p$-type in electrical conduction. As explained by Mandel [57] and John et al. [52], it is difficult to achieve $n$-type ZnTe thin films because of self-compensation. Researchers [58-60] who achieved $n$-type $\mathrm{ZnTe}$ semiconductors were able to accomplish this by using extrinsic doping. However, a recent report by Olusola et al. [45] revealed the possibility of realizing both $n$-type and $p$-type electroplated ZnTe semiconductors by intrinsic doping. They achieved the intrinsic doping by basically varying the growth voltage without the incorporation of external dopants such as chlorine, tin and aluminium. To further confirm the authenticity of developed $n$ - and $p$-type ZnTe materials, Olusola et al. [45] fabricated $p-n$ homo-junction diodes from the intrinsic $p$ - and $n$-ZnTe materials using device structure glass/FTO/n- ZnTe/ $p$-ZnTe/Au. The obtained results revealed the electronic device grade of the fabricated diodes. Apart from finding applications as homo-junction diodes, $p$-ZnTe films have also been used as an hetero-junction partner with $n$-CdS thin films in the fabrication of light emittind diodes [61], one-sided rectifying $p-n$ junction diodes [62] and photovoltaic cells $[63,64]$.

Thermal evaporation techniqe: $\mathrm{ZnTe}$ nanostructures have been synthesized by many methods such as chemical vapour deposition [65], radio frequency magnetron sputtering [66], reactive magnetron sputtering [67], chemical vapour deposition [68], sol-gel process [69], laser ablation [70] and spray pyrolysis [71] using different precursors [72,73]. Bhahada et al. [74] have synthesized uniform ZnTe thin films by the thermal evaporation method. Out of these techniques, thermal evaporation method has many advantages such as high deposition rate, real time rate and thickness control. Large charges can be loaded per deposition run. The evaporated substance is directed at the substrate placed above the source without any interference, by focusing the filament or aperture. The filament and focusing aperture do not heavily over coated. Material which is deposited sublime at lower temperature under vacuum. The selection of the substrates is wide. The films grown by this method have uniform thickness. Although the technology is low-cost in comparison to other physical vapour deposition method and easily available.

The ZnTe thin films were prepared using a vacuum coating unit (Hind High Vacuum Company, Bangalore, India) Model 12A4D. High purity Zn (99.998) and Te (99.998) were taken in the stoichiometric proportion for the preparation of $\mathrm{Zn}_{1-\mathrm{x}} \mathrm{Te}_{\mathrm{x}}$ alloys with varying composition with $\mathrm{x}=0.1,0.2$ and 0.3 . Each material of $\mathrm{ZnTe}$ was weighed by an electronic balance which has a resolu-tion of $\pm 0.0001 \mathrm{~g}$, according to percentage of composition to be used. The material $(\sim 100 \mathrm{mg})$ was placed into molybdenum boat and heated indirectly by passing current through the electr-odes. Cleaned glass slides were used as a substrate. The deposition has been done at vacuum of $10^{-5}$ torr. The obtained results revealed that ZnTe have cubical and hexagonal structure. Optical absorption data reveled that band of gap ZnTe thin film $2.57 \mathrm{eV}$.

Closed space sublimation: The fabrication of CdTe based solar cell can be achieved by closed space sublimation technique. The rough surface thin films are synthesized using closed space sublimation technique for solar cell applications [75-79]. The complete device with highest reported efficiency of more than $16 \%$ was fabricated using this technique along with chemical bath deposition. Closed space sublimation technique has some unique features, i.e. transport rate is high under moderate vacuum level, throughput is high and extremely high vapour pressure due to a small distance between source and the substrate. A small amount $(\sim 20 \mathrm{mg})$ is used to synthesize a thin film. Inverse proportional relation between growth rate and source-substrate distance for good quality films. Knudsen's expression best explains the high vapour pressure of closed space sublimation with other evaporation techniques [80].

$$
\frac{\mathrm{dN}}{\mathrm{dt}}=\mathrm{C}(2 \pi \mathrm{mkT})^{-1 / 2}\left(\mathrm{P}^{*}-\mathrm{P}\right)
$$

where $\mathrm{dN} / \mathrm{dt}$ is number of atoms per unit surface area $\left(\mathrm{cm}^{-2}\right)$; $\mathrm{C}$ is constant depend on rotational degree of freedom, $\mathrm{P}^{*}$ is vapour pressure of material at temperature $\mathrm{T}$ and $\mathrm{P}$ represents the vapour pressure above the surface.

The important deposition parameters are the distance between source and substrate, deposition time and ambient pressure and also the temperature gradient between source and substrate. Transportation of gas from source and sublimation on to the substrate is also an important deposition parameter in closed space sublimation technique. The conductivity of thin films is affected due to high deposition rate under low pressure. The larger grains are formed due to substrate temperature influence and also resistivity and mobility can be controlled with substrate temperature [81]. Fig. 1 showed the schematics of closed space sublimation technique.

Zinc Telluride (ZnTe) powder with high purity (99.99\%) was used as a source material and placed in a graphite boat. Soda lame glass slides were treated as substrates. The cleaning of substrates was achieved in ultrasonic bath with isopropanol, temperature of $60 \pm 5^{\circ} \mathrm{C}$ for $20 \mathrm{~min}$ and dried in air. A halogen lamp of $1000 \mathrm{~W}$ was used for direct heating of source material. The substrate temperature was carried out using $500 \mathrm{~W}$ halogen lamp usually known as substrate lamp under high vacuum of $10^{-5}$ mbar. K type thermocouples were introduced for temperature controller and connected with the main power supply. The source and substrate temperatures were maintained gradually after attaining the required high vacuum level.

Different sets of ZnTe thin films were prepared with source temperature of $450 \pm 5^{\circ} \mathrm{C}$. The substrate temperatures were $300 \pm 5^{\circ} \mathrm{C}, 3300 \pm 5^{\circ} \mathrm{C}$ and $360 \pm 5^{\circ} \mathrm{C}$ with the deposition time was $5 \mathrm{~min}$ for optimized deposition. Pre-annealing process was 


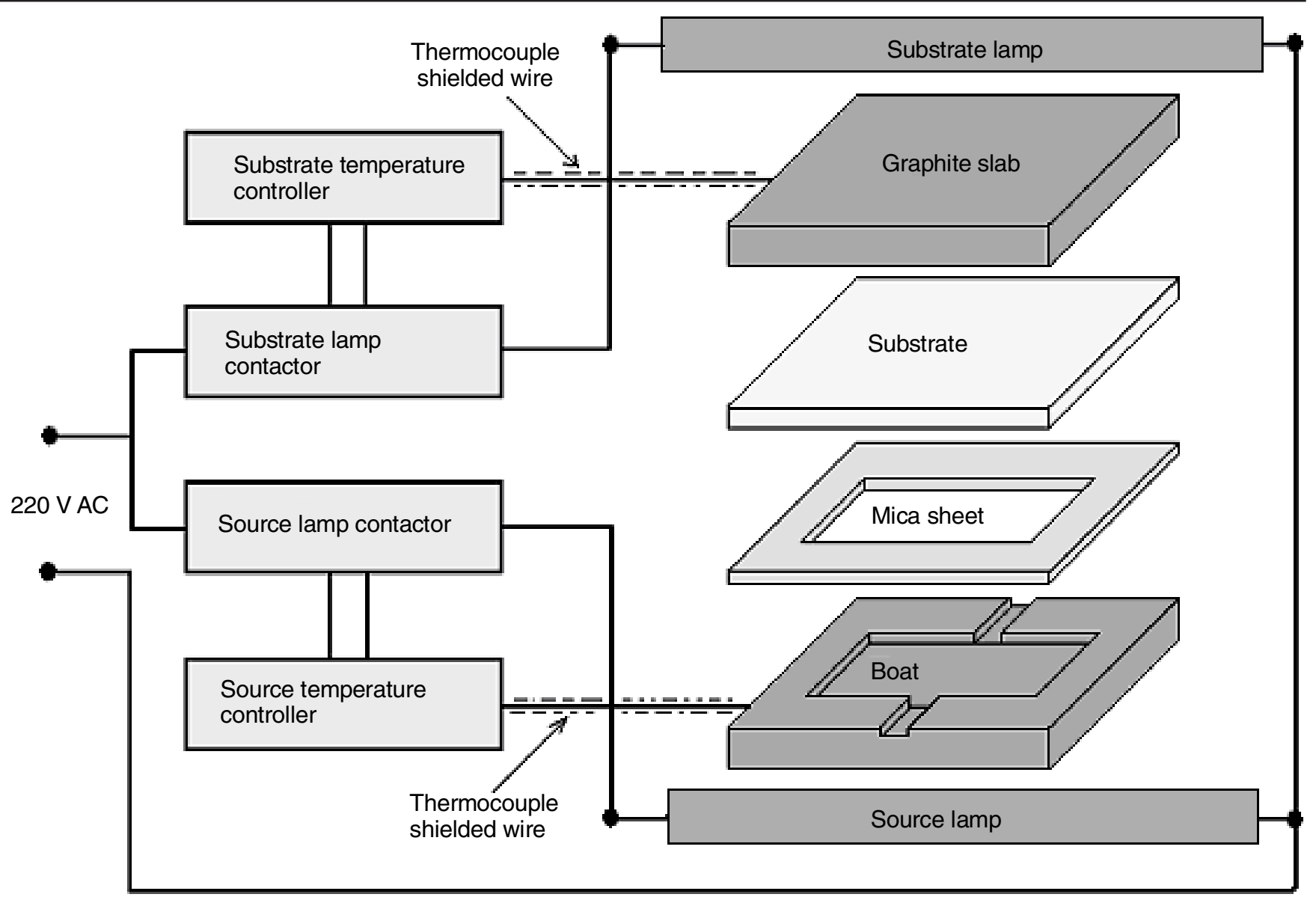

Fig. 1. Schematics of evaporation assembly of closed space sublimation

started once the required source and substrate temperatures achieved with deposition time, the source lamp was switched off and the substrate lamp was still 'on' till the source temperature was dropped to substrate temperature. At the end of deposition, the source-substrate temperatures were switched 'off' and the chamber was left for cooling down to room temperature under vacuum to avoid oxidation [75-81].

ZnTe thin films showed polycrystalline behaviour in X-ray diffraction (XRD) spectra (Fig. 2). The film had cubic structure with [111] direction confirmed by using International Card of Diffraction Data (ICDD) reference cards. The lattice constant 'a' is $6.0980 \AA$ A. Scherer's formula was used to calculate the crystallite size of ZnTe thin films [82]. The crystallite sizes were 30 to $60 \mathrm{~nm}$ ranges. The substrate temperature affects the crystallinity of the film's structure. The slow reaction between Te and $\mathrm{Zn}$ species was due to the thermal energy available at low temperature, which is very less in comparison with inter-diffusion of atoms. The quenching of atoms with the increase of substrate temperature on the substrate reduces the diffusion length and increases the mobility [81]. The deposition phenomena depend upon Te and $\mathrm{Zn}$ atoms diffusing on the substrate with the increase of substrate temperature. The reaction between $\mathrm{Te}$ and $\mathrm{Zn}$ increases with the thermal energy available for atoms arriving, would be responsible of good quality ZnTe thin films.

The high vapour pressure at the early deposition stages of Te material evolves with time for the vertical composition of $\mathrm{ZnTe}$ thin films. The rapid consumption of Te material with time results less as compared to $\mathrm{Zn}$ material, finally the amount of

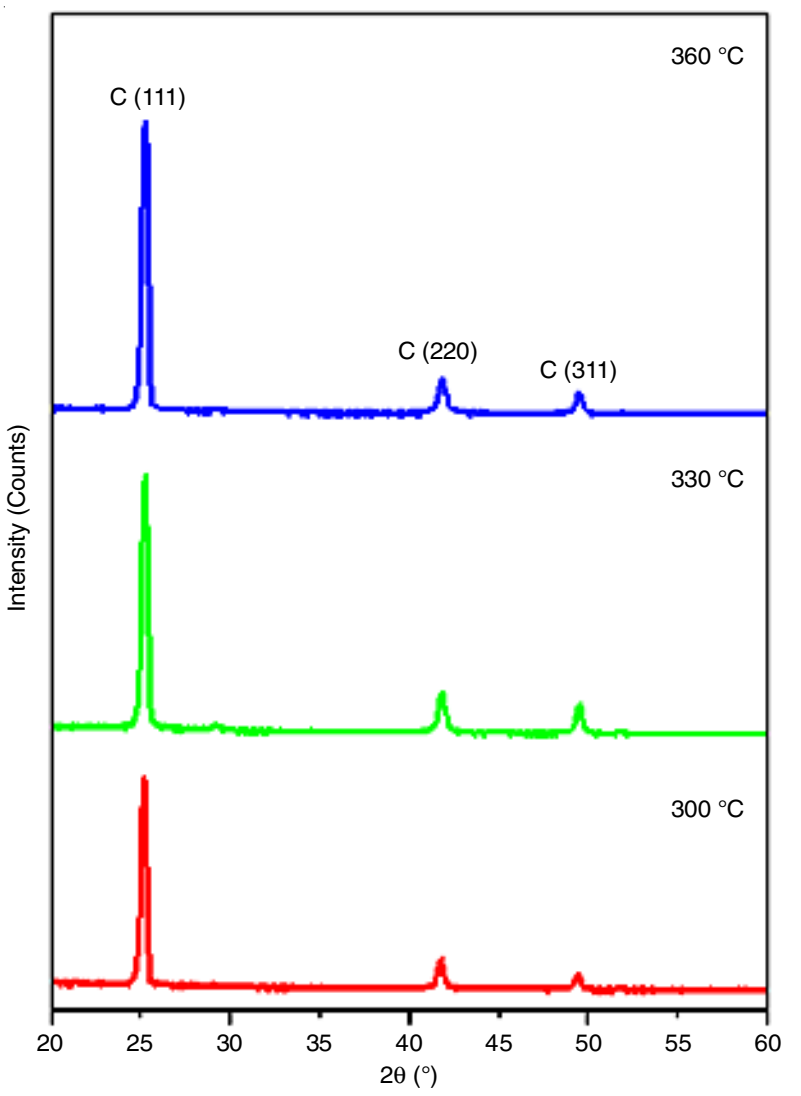

Fig. 2. XRD patterns of ZnTe films deposited at different substrate temperatures 
$\mathrm{Te}$ will be reduced. The vapour pressure of $\mathrm{Zn}$ will supersede Te material with time and result the increasing concentration of $\mathrm{Zn}$.

The discussion is applicable to other deposition techniques also like e-beam evaporation, sputtering, etc. but the important result regarding substrate temperature is noticed. The effects of substrate temperature on stoichiometry is remarkable using closed space sublimation technique. At low temperatures ranges, the Te vapour pressure is high so Te is in excess ZnTe thin films.

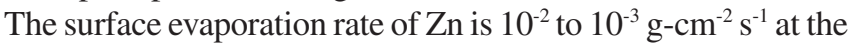
temperature range less than $500^{\circ} \mathrm{C}$, so Te is less than $\mathrm{Zn}$ at this temperature ranges. The materials who has high vapour pressure vapourizes more rapidly the lower vapour pressure [81]. The smaller amount of material's atom or molecules will be more moveable at any substrate temperature, Te atoms have chance to make a bond with $\mathrm{Zn}$ atoms bond regardless the amount of $\mathrm{Zn}$ in films and the crystallinity will be better at higher substrate temperature. In closed space sublimation technique, the sourcesubstrate temperature is kept $5 \mathrm{~mm}$, therefore the vapour pressure of Te and $\mathrm{Zn}$ is very high due to small proximity. Such a high vapour pressure is not possible in other techniques like sputtering or e-beam evaporation due to large source-substrate distances as a result the evaporated species flux is not high. The stoichiometry is improved with increasing substrate temperature of Te- $\mathrm{Zn}$ reaction. Therefore, the inter-sticking will be enhanced.

The diffusion length and mobility of $\mathrm{Zn}$ and Te species at higher temperature will result the increase in crystallite size from 37 to $63 \mathrm{~nm}$. The surface diffusion has relaxing time larger for mobile atoms to settle at crystal site due to elevated temperature increase. Rearrangement among the small crystallites to form larger grains at higher temperatures [81]. With the help of above discussion, the dislocation density and strain decreases from $7.2 \times 10^{-4}$ to $2.5 \times 10^{-4} \mathrm{~nm}^{-2}$ and $9.3 \times 10^{-4}$ to $5.5 \times 10^{-4} \mathrm{~nm}^{-2}$, respectively.

As a result of the above section, closed space sublimation technique has a high vapour pressure at elevated substrate temperature so the ad-atoms move towards lattice sites with high energy at favourable places resulting larger crystallite sizes also reduces the imperfections in as-grown $\mathrm{ZnTe}$ thin films $[83,84]$.

\section{Conclusion}

There are various techniques have been employed for deposition of zinc telluride thin films, namely thermal evaporation, closed space sublimation and electrodeposition. It is concluded that a lot of variation in the results reported by different researchers from these deposition methods.

\section{ACKNOWLEDGEMENTS}

One of the authors, (SMH) thank INTI International University, Malaysia while another author (WM) thanks Thin Films Technology Research Laboratory, Department of Physics, COMSATS Institute of Information Technology, Islamabad, Pakistan for providing the necessary research facilities.

\section{REFERENCES}

1. S.S. Tulenin, E.V. Maraeva, L.N. Maskaeva and V.F. Markov, Asian J. Chem., 29, 995 (2017); https://doi.org/10.14233/ajchem.2017.20385.

2. A. Kaur and R. Kumar, Asian J. Chem., 29, 1990 (2017); https://doi.org/10.14233/ajchem.2017.20712.
3. H. Sarma, D. Chakrabortty and K.C. Sarma, Asian J. Chem., 29, 2005 (2017); https://doi.org/10.14233/ajchem.2017.20726.

4. S. Vyas, Asian J. Chem., 29, 2341 (2017); https://doi.org/10.14233/ajchem.2017.20696.

5. A.H. Abdullah, S.M. Ho and K. Anuar, Av. Quim., 5, 141 (2010).

6. H.J. Ahmad, K. Anuar, S.M. Ho, W.T. Tan, H.A. Abdul and N. Saravanan, Kasetsart J. (Nat. Sci.), 44, 446 (2010).

7. G. Bakiyaraj and R. Dhanasekaran, Appl. Nanosci., 3, 125 (2013); https://doi.org/10.1007/s13204-012-0075-y.

8. K. Anuar, S.M. Ho, Y.Y. Loh and N. Saravanan, Silpakorn Univ. Sci. Technol., 4, 36 (2010).

9. M.M. Al-Jassim, Y. Yan, H.R. Moutinho, M.J. Romero, R.D. Dhere and K.M. Jones, Thin Solid Films, 387, 246 (2001); https://doi.org/10.1016/S0040-6090(00)01707-7.

10. S.M. Ho, K. Anuar, W.T. Tan, H.A. Abdul and N. Saravanan, Maced. J. Chem. Chem. Eng., 29, 97 (2010); https://doi.org/10.20450/mjcce.2010.178

11. T.S. Kumaran, S.P. Banu, C. Kamal and G. Venkatesh, Asian J. Chem., 29, 779 (2017); https://doi.org/10.14233/ajchem.2017.20280.

12. S.M. Ho, K. Anuar and W.T. Tan, Universal J. Chem., 1, 170 (2013).

13. P. Wang, C. Li, F. Wang, J. Ou and M. Xue, Asian J. Chem., 28, 325 (2016); https://doi.org/10.14233/ajchem.2016.19300.

14. H. Soonmin, Asian J. Chem., 27, 3851 (2015); https://doi.org/10.14233/ajchem.2015.19013.

15. P.S. Joshi, S.M. Jogade, S.D. Gothe and D.S. Sutrave, Asian J. Chem., 29, 203 (2017); https://doi.org/10.14233/ajchem.2017.20378.

16. A. Kassim, M.Y. Rosli and H.S. Min, Int. J. Chemtech Res., 3, 21 (2011); https://doi.org/10.9735/0975-3699.3.1.21-26.

17. I.Y. Erdogan, T. Öznülüer, F. Bülbül and Ü. Demir, Thin Solid Films, 517, 5419 (2009) https://doi.org/10.1016/j.tsf.2009.01.018.

18. H. Jelas, S.M. Ho, K. Anuar and S. Atan, Orient. J. Chem., 27, 1375 (2011).

19. S.S. Kamble, A. Sikora, S.T. Pawar, N.N. Maldar and L.P. Deshmukh, J. Alloys Comp., 623, 466 (2015); https://doi.org/10.1016/j.jallcom.2014.10.183.

20. N. Kamoun, H. Bouzouita and B. Rezig, Thin Solid Films, 515, 5949 (2007); https://doi.org/10.1016/j.tsf.2006.12.144.

21. A. Kassim, T.W. Tee, H.S. Min, S. Monohorn and S. Nagalingam, Kathmandu U. J. Sci. Eng. Technol., 6, 126 (2010); https://doi.org/10.3126/kuset.v6i2.4021.

22. J. Kang, I. Ryu, G. Choe, G. Kim and S. Yim, Int. J. Electrochem. Sci., 12, 9588 (2017); https://doi.org/10.20964/2017.10.27.

23. A. Kassim, S.M. Ho, W.T. Tan, A. Shariff and N. Saravanan, Eur. J. Appl. Sci., 3, 113 (2011).

24. W.T. Tan, S.M. Ho and K. Anuar, Eur. J. Sci. Res., 66, 592 (2011).

25. M. Yazid, K. Anuar, S.M. Ho, W.T. Tan, A.H. Abdullah and H. Jelas, Orient. J. Chem., 25, 813 (2009).

26. K. Zulkefly, K. Anuar, N. Saravanan, S.M. Ho, W.T. Tan and S. Atan, Indian J. Eng. Mater. Sci., 17, 295 (2010).

27. N. Saravanan, K. Anuar, S.M. Ho, W.T. Tan, S. Atan and M. Kuang, $J$. Appl. Sci. Res., 4, 1701 (2008).

28. S.B. Segu, M.R. Chandra, K.S. Saravana, A. Ayeshamariam and M. Jayachandran, Fluid Mech. Open Access, 4, 156 (2017); https://doi.org/10.4172/2476-2296.1000156.

29. N. Saravanan, K. Anuar, S.M. Ho, H.A. Abdul and K. Noraini, Dig. J. Nanomater. Biostruct., 5, 975 (2010).

30. L.K. Siang, K. Anuar, S.M. Ho and S. Nagalingam, Sultan Qaboos U. J. Sci., 16, 24 (2011); https://doi.org/10.24200/squjs.vol16iss0pp24-33.

31. J.H. Mohd, S.M. Ho and K. Anuar, J. Pharm. Life Sci., 2, 1190 (2011).

32. M.F. Gromboni and L.H. Mascaro, J. Electroanal. Chem., 780, 360 (2016); https://doi.org/10.1016/j.jelechem.2016.04.037.

33. D. Han, S. Choi and S. Park, J. Electrochem. Soc., 150, C342 (2003); https://doi.org/10.1149/1.1565136.

34. J. Pattar, S.N. Sawant, M. Nagaraja, N. Shashank, K.M. Balakrishna, G. Sanjeev and H.M. Mahesh, Int. J. Electrochem. Sci., 4, 369 (2009).

35. T. Ishizaki, T. Ohtomo and A. Fuwa, J. Phys. D: Appl. Phys., 37, 255 (2004); https://doi.org/10.1088/0022-3727/37/2/014.

36. T. Potlog, N. Maticiuc, A. Mirzac, P. Dumitriu and D. Scortescu, Semiconductor Conference 2012 International, vol. 2, p. 321 (2012). 
37. V. Palekis, D. Shen, D. Hodges, S. Bhandaru, E. Stefanakos, D.L. Lorel and C.S. Ferekides, Structural properties of CdTe and ZnTe Thin Films Deposited on Flexible Foil Substrates, $35^{\text {th }}$ IEEE Photovoltaic Specialists Conference, Honolulu, HI, USA, 20-25 June 2010(2010); https://doi.org/10.1109/PVSC.2010.5616690.

38. V. Kumar, V. Kumar and D.K. Dwivedi, Phys. Scr, 86, 15604 (2012); https://doi.org/10.1088/0031-8949/86/01/015604.

39. J. De Merchant, J. Electrochem. Soc., 143, 4054 (1996); https://doi.org/10.1149/1.1837335.

40. L.S. Adam, Doctor of Philosophy. Retrospective Theses and Dissertations, 405 (2002). http://lib.dr.iastate.edu/rtd/405.

41. A.M. Aboraia, M. Ahmad, E.A.A. Wahab, H.S. Hassan and E.R. Shaaban, Int. J. New Hor. Phys., 2, 11 (2015).

42. D.K. Dwivedi, D. Ashankar and D. Maheshwar, Rom. J. Phys., 55, 352 (2010).

43. G.I. Rusu, P. Prepelita, N. Apetroaei and G. Popa, J. Optoelectron. Adv. Mater, 7, 829 (2005).

44. T. Nakasu, W. Sun, M. Kobayashi and T. Asahi, J. Cryst. Growth, 468, 635 (2017); https://doi.org/10.1016/j.jcrysgro.2016.11.035.

45. O.I. Olusola, M.L. Madugu, N.A. Abdul-Manaf and I.M. Dharmadasa, Curr. Appl. Phys., 16, 120 (2016); https://doi.org/10.1016/j.cap.2015.11.008.

46. O.I. Olusola, M.L. Madugu and I.M. Dharmadasa, Mater. Res. Innov., 19, 497 (2015); https://doi.org/10.1080/14328917.2015.1105570.

47. B.M. Basol and V.K. Kapur, Thin Solid Films, 165, 237 (1988); https://doi.org/10.1016/0040-6090(88)90694-3.

48. M. Neumann-Spallart and C. Königstein, Thin Solid Films, 265, 33 (1995); https://doi.org/10.1016/0040-6090(95)06641-1.

49. T. Mahalingam, V.S. John, S. Rajendran, G. Ravi and P.J. Sebastian, Surf. Coat. Technol., 155, 245 (2002); https://doi.org/10.1016/S0257-8972(02)00117-2.

50. F. Fauzi, D.G. Diso, O.K. Echendu, V. Patel, Y. Purandare, R. Burton and I.M. Dharmadasa, Semicond. Sci. Technol., 28, 045005 (2013); https://doi.org/10.1088/0268-1242/28/4/045005.

51. D.G. Diso, F. Fauzi, O.K. Echendu, A.R. Weerasinghe and I.M. Dharmadasa, J. Phys. Conf. Ser., 286, 012040 (2011); https://doi.org/10.1088/1742-6596/286/1/012040.

52. V.S. John, T. Mahalingam and J.P. Chu, State. Electron., 49, 3 (2005); https://doi.org/10.1016/j.sse.2004.07.015.

53. M.S. Hossain, R. Islam and K.A. Khan, Renew. Energy, 33, 642 (2008); https://doi.org/10.1016/i.renene.2007.04.003.

54. N.B. Chaure, R. Jayakrishnan, J.P. Nair and R.K. Pandey, Semicond. Sci. Technol., 12, 1171 (1997); https://doi.org/10.1088/0268-1242/12/9/018.

55. A.B.M.O. Islam, N.B. Chaure, J. Wellings, G. Tolan and I.M. Dharmadasa, Mater. Charact., 60, 160 (2009); https://doi.org/10.1016/j.matchar.2008.07.009.

56. T. Gandhi, K.S. Raja and M. Misra, Thin Solid Films, 517, 4527 (2009); https://doi.org/10.1016/j.tsf.2008.12.046.

57. G. Mandel, Phys. Rev., 134(4A), A1073 (1964); https://doi.org/10.1103/PhysRev.134.A1073.

58. I.W. Tao, M. Jurkovic and W.I. Wang, Appl. Phys. Lett., 64, 1848 (1994); https://doi.org/10.1063/1.111775.

59. J.H. Chang, T. Takai, B.H. Koo, J.S. Song, T. Handa and T. Yao, Appl. Phys. Lett., 79, 785 (2001); https://doi.org/10.1063/1.1390481.
60. V.P. Makhny and V.I. Grivul, Semicond., 40, 774 (2006); https://doi.org/10.1134/S1063782606070062.

61. T. Ota, K. Kobayashi and K. Takahashi, Solid-State Electron., 15, 1387 (1972); https://doi.org/10.1016/0038-1101(72)90134-7.

62. O.I. Olusola, H.I. Salim and I.M. Dharmadasa, Mater. Res. Express, 3, 095904 (2016);

https://doi.org/10.1088/2053-1591/3/9/095904.

63. F. Pfisterer and H.W. Schock, J. Cryst. Growth, 59, 432 (1982); https://doi.org/10.1016/0022-0248(82)90364-5.

64. O.I. Olusola, PhD Thesis, Sheffield Hallam University, Sheffield (2016). http://shura.shu.ac.uk/id/eprint/14127.

65. B. Cheng and E.T. Samulski, Chem. Commun., 8, 986 (2004); https://doi.org/10.1039/b316435g.

66. Z.Y. Fan, D.W. Wang, P.C. Chang, W.Y. Tseng and J.G. Lu, Appl. Phys. Lett., 85, 5923 (2004); https://doi.org/10.1063/1.1836870.

67. Z.-C. Jin, I. Hamberg and C.G. Granqvist, J. Appl. Phys., 64, 5117 (1988); https://doi.org/10.1063/1.342419.

68. O.F.Z. Khan and P. O'Brien, Thin Solid Films, 173, 95 (1989); https://doi.org/10.1016/0040-6090(89)90541-5.

69. Y. Ohya, H. Saiki and Y. Takahashi, J. Mater. Sci., 29, 4099 (1994); https://doi.org/10.1007/BF00355977.

70. Z.Y. Ning, S.H. Cheng, S.B. Ge, Y. Chao, Z.Q. Gang, Y.X. Zhang and Z.G. Liu, Thin Solid Films, 307, 50 (1997); https://doi.org/10.1016/S0040-6090(97)00303-9.

71. S. Major, A. Banerjee and K.L. Chopra, Thin Solid Films, 108, 333 (1983); https://doi.org/10.1016/0040-6090(83)90082-2.

72. B.D. Cullity and S.R. Stock, Elements of X-Ray Diffraction, Preventice Hall (2001).

73. Y.C. Zhang, X. Wu, X. Ya Hu and R. Guo, J. Cryst. Growth, 280, 250 (2005) https://doi.org/10.1016/j.jcrysgro.2005.03.001.

74. K.C. Bhahada, B. Tripathi, N.K. Acharya, P.K. Kulriya and Y.K. Vijay, Appl. Surf. Sci., 255, 2143 (2008) https://doi.org/10.1016/j.apsusc.2008.07.068

75. W. Mahmood, A. Thomas, A. Haq, N.A. Shah and M.F. Nasir, J. Phys. D: Appl. Phys., 50, 255503 (2017); https://doi.org/10.1088/1361-6463/aa7157.

76. W. Mahmood and N.A. Shah, AIP Conf. Proc., 1476, 178 (2012); https://doi.org/10.1063/1.4751590.

77. N.A. Shah and W. Mahmood, Thin Solid Films, 544, 307 (2013); https://doi.org/10.1016/j.tsf.2013.03.088.

78. W. Mahmood and N.A. Shah, Curr. Appl. Phys., 14, 282 (2014); https://doi.org/10.1016/j.cap.2013.11.021.

79. W. Mahmood and N.A. Shah, Opt. Mater, 36, 1449 (2014); https://doi.org/10.1016/i.optmat.2013.09.003.

80. W. Mahmood, N.A. Shah and S. Akram, Chalcogenide Lett., 10, 273 (2013)

81. K.L. Chopra and S.R. Das, Thin Film Solar Cells, Plenum Press, New York (1983)

82. G.U. Siddiqui, J. Ali, Y. Doh and K. Choi, Mater. Lett., 166, 311 (2016); https://doi.org/10.1016/j.matlet.2015.12.045.

83. N.A. Shah, M. Abbas, W.A. Syed and W. Mahmood, Iran J. Energy Environ., 5, 87 (2014); https://doi.org/10.5829/idosi.ijee.2014.05.01.13.

84. M.U. Farooq, S. Butt, K. Gao, X. Sun, X.L. Pang, A. Mahmood, W. Mahmood, S.U. Khan and N. Mahmood, Sci. China Mater, 59, 135 (2016); https://doi.org/10.1007/s40843-016-0126-x. 